DOI: $10.12731 /$ wsd-2018-4-51-71

УДК 616.988:616-071.2:616-037:616.8-009:616-036.11

\title{
КЛИНИЧЕСКИЕ ПРОГНОСТИЧЕСКИЕ КРИТЕРИИ ОЧАГОВОЙ ФОРМЫ ОСТРОГО КЛЕЩЕВОГО ЭНЦЕФАЛИТА
}

\section{Ильинских Е.Н., Ильинских Н.Н., Замятина Е.В.}

Цель. Выявить основные клинические прогностические критерии ранней диагностики очаговой формы (ОФ) клещевого эниефалита (КЭ), создать модели бинарной логистической регрессии и составить диагностические алгоритмы, позволяюшие дифференцировать очаговую и менингеальную формы (МФ) заболевания.

Материалы и методы. Проведено ретроспективное клиническое исследование типа «случай-контроль» с анализом рутинных данных историй болезней 138 паииентов с подтвержденным диагнозом МФ и 26 больных ОФ острого КЭ. Все полученные данные были занесены в компьютерную базу данных, которая была подвергнута статистическому анализу с применением программного обеспечения Epi Info, версия 3.3 .2 (США) $и$ приложения Scorecard STATISTICA 12.0 (StatSoft, США) для создания диагностических моделей. Оиенка качества прогноза модели проведена с помощью ROC (receiver operating characteristic)-анализа.

Результаты. Проведенное исследование позволило выделить наиболее прогностически значимые для ранней диагностики ОФ параметры объективного и неврологического статусов. К ним можно отнести: возраст больного более 41 года, частоту пульса более 80 в мин, показатели систолического давления более 130 мм pm. ст., нарушение речи и сознания, функции черепных нервов, координации движений и исчезновение брюшных рефлексов. Кроме того, к числу дополнительных факторов существенно повышающих риск летального исхода при ОФ КЭ можно отнести наличие у больного сахарного диабета, гипертонической болезни, ишемической болезни сердиа и ожирение.

Заключение. На основе полученных данных созданы три модели и составлены диагностические алгоритмы, позволяющие улучшить тактику ведения больных за счет раннего прогнозирования развития ОФ КЭ.

Ключевые слова: клещевой энщефалит; очаговая форма; предиктоpы; модель логистической регрессии; ROC-анализ. 


\title{
CLINICAL PREDICTIONAL CRITERIA FOR ENCEPHALITIC FORM OF ACUTE TICK-BORNE ENCEPHALITIS
}

\author{
Ilyinskikh E.N., Ilyinskikh N.N., Zamyatina E.V.
}

Background. The aims of this study were to identify the main clinical predictors of mono(multi)focal encephalitis form (EF) of tick-borne encephalitis (TBE), develop binary logistic regression models, standardized questionnaire, and scoring system to differentiate between EF and meningeal form (MF) of this disease.

Materials and methods. A retrospective clinical case-control study was carried out to analyze routine data of the case history files of 138 MF patients and 26 patients with EF of TBE. All the data obtained were recorded in a computer database that was analyzed statistically using Epi Info software, version 3.3.2 (USA) and Scorecard STATISTICA 12.0 (StatSoft, USA) applications for development of diagnostic models. To assess the predictive power of the scorecard model, the ROC (receiver operating characteristic) curve analysis was carried out.

Results. The study enabled to identify the most significant predictors of physical and neurological examination for the early diagnosis of EF of TBE. These predictors included the following characteristics: the patient's age was more than 41 years, pulse rate was more than 80 per min, systolic arterial pressure was over $130 \mathrm{~mm} \mathrm{Hg}$, dysfunction of cranial nerves, speech, consciousness, coordination of movements, and the disappearance of abdominal reflexes. Moreover, diabetes, hypertension, ischemic heart disease, and obesity were the additional predictors that were able to significantly increase the risk of a lethal outcome in the EF patients.

Conclusion. As the results of this study three models were built and diagnostic scoring systems were developed to improve the management of the patients due to early prognosis for FEF of TBE.

Keywords: tick-borne encephalitis; encephalitic form; predictors; logistic regression model; ROC curve analysis.

Клещевой энцефалит (КЭ) является одной из наиболее распространенных природно-очаговых инфекций Западной и Восточной Сибири и, в особенности, Томской области [1]. Известно, что это заболевание может приводить к развитию очаговых форм (ОФ) с тяжелым поражением центральной нервной системы, высоким риском инвалидизации и летально- 
го исхода. Одной из трудных проблем диагностики КЭ является раннее распознавание ОФ, которую в начале заболевания сложно дифференцировать от менингеальной формы (МФ) [2]. Одной из современных направлений диагностики некоторых тяжело протекающих инфекционных заболеваний является разработка компьютерных диагностических алгоритмов и шкал, которые могли бы использоваться практическими врачами для определения тяжести и прогнозирования исходов заболевания [3]. Поэтому целью данной работы было помощью комплексного ретроспективного статистического анализа рутинных данных историй болезни выявить основные клинические прогностические критерии ранней диагностики очаговой формы болезни и составить диагностические алгоритмы, позволяющие дифференцировать ОФ и МФ КЭ. Для полноценного выполнения вышеприведенной цели была поставлена задача проанализировать данные с помощью бинарной логистической регрессии, позволяющей создать модели оценочных алгоритмов.

\section{Материалы и методы}

Работа выполнена в дизайне ретроспективного клинического исследования типа «случай-контроль» на базах клиники инфекционных заболеваний ФГБОУ ВО Сибирского государственного медицинского университета и инфекционного отделения ОГАУЗ 3 -ей Городской больницы г. Томска в период эпидсезонов КЭ в 2005-2016 годов. Мы включили в исследование 138 пациентов с подтвержденным диагнозом менингеальной формы (группа МФ) и 26 больных очаговой формой (группа ОФ) острого КЭ, в возрасте от 18 до 88 лет, которые были госпитализированы в выше названные стационары за период 10 лет. Среди больных ОФ преобладали больные менингоэнцефалитическим вариантом. Вместе с тем у 3 пациентов был диагностирован полиоэнцефаломиелитический вариант, а у 6 больных заболевание закончилось летальным исходом. Известно, что общепринятая клиническая классификация КЭ отсутствует. Мы использовали клиническую классификацию, предложенную в 2014 г Национальным научным обществом инфекционистов в клинических рекомендациях «Клещевой вирусный энцефалит у взрослых». В соответствии с этой классификацией все клинически манифестно протекающие случаи заболевания разделяют на неочаговые, включающие лихорадочную и менингеальную формы, и очаговые формы, к которым относят менингоэнцефалитический, полиоэнцефалитический, полиоэнцефалимиелитический и полиомиелитический варианты [4]. 
Клиническая картина менингеальной формы характеризовалась сочетанием токсико-инфекционного, менингеального, гипертензионного и ликворологического синдромов (плеоцитоз смешанного или преимущественно лимфоцитарного характера более 10 клеток / мкл). Критериями отнесения случаев к очаговой форме (менингоэнцефалит) было доминирование в клинической картине общемозговых, центральных парезов, судорожных симптомов, расстройство сознания различной степени, вплоть до комы [4].

Во всех случаях диагноз был верифицирован методом твердофазного иммунофермерного анализа (ИФА) в случае обнаружения положительных титров сывороточных иммуноглобулинов ( $\mathrm{Ig}$ ) класса М или одновременно IgM и IgG к вирусу КЭ с применением тест-систем ЗАО «Вектор-Бест» (г. Кольцово, Россия). Исследование сыворотки крови проводили в динамике при поступлении больного в стационар (не ранее 6-7 дня от начала заболевания) и через 10-14 дней. Кроме того, для исключения сопутствующей патологии определялись титры IgM и $\operatorname{IgG}$ к боррелиям иксодового клещевого боррелиоза (ИКБ) в сыворотке крови, выявлялась РНК энтеровирусов в спинномозговой жидкости с помощью полимеразной цепной реакции (ПЦР), а также проводилось бактериологическое исследование ликвора на менингококк и группу условно-патогенных бактерий.

Информированное согласие на участие в исследовании было получено от всех участников. Исследование было одобрено Этическим комитетом ФГБОУ ВО «Сибирского государственного медицинского университета» Минздрава РФ (протокол № 23 от 19.10.2015 г.) и проводилось в соответствии с правилами «О порядке проведения биомедицинских исследований у человека» (2002 г.) и «Правилами клинической практики» (Приказ МЗ РФ № 266 от 19.06.03).

Проведено изучение историй болезни, откуда получена информация об эпидемиологическом анамнезе, жалобах, объективном статусе и неврологическом статусе. Во время госпитализации наличие признаков оценивались и регистрировались ежедневно, что позволило оценить продолжительность основных симптомов. Вся полученная информация была занесена в базу данных, в которой были отражены: возраст, пол больного, данные эпидемиологического характера (наличие или отсутствие достоверных сведений о присасывании или наползании клеща, количество снятых с больного клещей, локализации укуса клеща на теле (голова, грудная клетка, живот, верхние и нижние конечности), проведение экстренной профилактики антибиотиками и донорским иммуноглобулином человека против клещевого энцефалита, продолжительность инкубационного пери- 
ода); данные жалоб при поступлении больного в стационар (головная боль, головокружение, гиперестезия, тошнота, рвота, боли в мышцах, чувство онемения в конечности); показания температура тела, артериального давления, частоты пульса и дыхания; данные неврологического статуса (включавшие нарушение сознания, наличие судорожного синдрома, изменения речи, походки, пальце-носовой пробы, устойчивости в позе Ромберга, изменения объема движения тонуса и силы мышц в конечностях, парезы черепных нервов, глубокие и поверхностные рефлексы и менингеальные симптомы). Все выше перечисленные параметры в базе данных были представлены как количественные или качественные показатели в виде единицы в случае наличия симптома (признака) или нуля при его отсутствии.

Для обработки данных и статистического анализа применялось программное обеспечение STATISTICA 12.0 (StatSoft, CШA), а также Epi Info, версия 3.3.2 (Центр контроля и профилактики заболеваний, США) [5]. Различия качественных данных между группами были проанализированы с помощью критерия значимости гипотезы $\chi^{2}$ или точного критерия Фишера, а также коэффициента взаимной сопряженности (К) [5]. Кроме того, некоторые результаты были представлены как $\mathrm{p} \pm S$, где $\mathrm{p}$ - выборочная доля, а $S_{p}$ - стандартная ошибка выборочной доли. При проверке статистических гипотез двусторонние значения $\mathrm{P}<0,05$ были интерпретированы как статистически значимые [5].

С помощью специализированных модулей приложения Scorecard программного обеспечения STATISTICA 12.0 (StatSoft, CШA) [6, 7], предназначенных для разработки и оценки моделей оценочных алгоритмов, были созданы алгоритмы диагностического поиска, позволяющие дифференцировать ОФ и МФ КЭ. Вначале была создана расширенная модель, включающая данные всех параметров, проанализированных в историях болезней. Затем с помощью модуля, определяющего информационную ценность каждого показателя, была дана оценка их прогностической силы и исключены все несущественные или избыточные переменные из первоначального набора параметров. В модуле анализа качественной переменной были подготовлены профили рисков и весовые коэффициенты доказательности для каждого показателя. На основе результатов модуля анализа качественной переменной и бинарной логистической регрессии в модуле Scorecard была созданы оценочная система и сгенерирована шкала в баллах для каждой модели $[6,7]$. Известно, что, бинарный логистический регрессионный анализ исследует связь между набором зависимых качественных переменных и независимой переменной, в качестве которой в данной работе послужили клинические 
формы КЭ: для ОФ выбрано значение 1, а для МФ использовано значение $0[6,7]$. Прогностическая оценка диагностической модели проведена с помощью последовательного статистического анализа Вальда и ROC (receiver operating characteristic)-анализа в координатах графиков «чувствительностьспецифичность» с вычислением AUC (area under ROC curve) - площади под ROC-кривой и COV (cut-off value) - значения оптимального порога отсечения переменной [8]. Кроме того, использованы стандартные критерии точности бинарных диагностических тестов (чувствительность, специфичность, отрицательные и положительные прогностические значения). Для оценки качества прогноза как отдельных изученных параметров, так и разработанных моделей использовалось определение площади под ROC-кривой AUC (варьирует в пределах 0-1). Среди клинических параметров был выполнен поиск наиболее информативных предикторов прогнозирования ОФ КЭ. Во внимание принимались показатели со «средним» (AUC > 0,6), «хорошим» $(\mathrm{AUC}>0,7)$, «очень хорошим» $(\mathrm{AUC}>0,8)$ и «отличным» качеством прогнозирования $(\mathrm{AUC}>0,9)[8]$. Для каждой модели проведен расчет cut-off oптимальных порогов отсечения в баллах с учетом значений чувствительности и специфичности, которые соответствуют границам между интервалами показателей и позволяют достоверно разделить ОФ и МФ КЭ.

\section{Результаты исследования и их обсуждение}

В таблицах 1 и 2 проанализированы основные параметры, полученные из историй болезней, которые имели статистически значимые отличия между группами больных с ОФ и МФ КЭ.

Таблица 1.

Анализ эпидемиологических и клинических предикторов очаговой формы клещевого энцефалита

\begin{tabular}{|c|c|c|c|c|c|}
\hline \multirow{2}{*}{ Предикторы } & \multicolumn{2}{|c|}{$\begin{array}{c}\text { Частота (\%) в } \\
\text { группах больных }\end{array}$} & \multirow{2}{*}{ ОШ (95\%ДИ) } & \multirow{2}{*}{$\chi^{2}$} & \multirow{2}{*}{$P$} \\
\hline & $\begin{array}{c}\text { ОФ КЭ } \\
\mathrm{n}=26\end{array}$ & 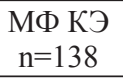 & & & \\
\hline \multicolumn{6}{|l|}{ Эпиданамнез } \\
\hline Возраст > 41 года & 65,0 & 27,8 & $4,8(1,6-14,3)$ & 8,6 & 0,003 \\
\hline Возраст > 69 лет & 25,0 & 3,7 & $8,7(1,2-96,0)$ & 5,4 & 0,019 \\
\hline $\begin{array}{l}\text { Локализация присасывания } \\
\text { клеща в области головы и шеи }\end{array}$ & 35,0 & 3,70 & $14,0(2,6-75,5)$ & 13,4 & 0,0003 \\
\hline $\begin{array}{l}\text { День поступления в стационар } \\
\text { от начала болезни, > } 14 \text { дней }\end{array}$ & 57,1 & 24,0 & $4,2(1,23-14,36)$ & 5,69 & 0,017 \\
\hline
\end{tabular}


Окончание табл. 1.

\begin{tabular}{|c|c|c|c|c|c|}
\hline $\begin{array}{l}\text { Сопутствующие } \\
\text { заболевания }\end{array}$ & & & & & \\
\hline $\begin{array}{l}\text { Число заболеваний } \\
\geq 2\end{array}$ & 66,7 & 2,2 & $25,7(7,2-91,8)$ & 37,8 & $<0,001$ \\
\hline Сахарный диабет & 33,3 & 3,8 & $12,6(3,9-40,8)$ & 25,4 & $<0,001$ \\
\hline Гипертоническая болезнь & 37,5 & 5,1 & $11,2(3,8-33,3)$ & 25,7 & $<0,001$ \\
\hline Ишемическая болезнь сердца & 25,0 & 3,2 & $10,1(2,80-36,6)$ & 17,4 & $<0,001$ \\
\hline Ожирение, $\geq 2$ ст. & 23,3 & 1,9 & $15,6(3,8-64,7)$ & 22,8 & $<0,001$ \\
\hline \multicolumn{6}{|l|}{ Жалобы } \\
\hline $\begin{array}{l}\text { Продолжительность: } \\
\text { • боли в спине > } 19 \text { дней }\end{array}$ & 30,0 & 9,3 & $4,2(1,1-15,8)$ & 4,9 & 0,026 \\
\hline - тошноты $\geq 17$ дней & 65,0 & 38,9 & $2,9(1,0-8,5)$ & 4,0 & 0,045 \\
\hline - головной боли > 17 дней & 75,0 & 48,2 & $3,2(1,0-10,2)$ & 4,3 & 0,039 \\
\hline $\begin{array}{l}\text { - нарушения зрения } \geq 20 \\
\text { дней }\end{array}$ & 35,7 & 7,4 & $6,9(1,6-30,9)$ & 7,8 & 0,0053 \\
\hline $\begin{array}{l}\text { - чувства онемения в конеч- } \\
\text { ности } \geq 20 \text { дней }\end{array}$ & 35,7 & 12,9 & $3,7(0,9-14,4)$ & 3,9 & 0,047 \\
\hline - боли в мышцах $\geq 15$ дней & 60,0 & 29,6 & $3,6(1,2-10,4)$ & 5,7 & 0,016 \\
\hline
\end{tabular}

Примечание: МФ - менингеальная форма; ОФ - очаговая (менингоэнцефлитическая) форма; ОШ - отношение шансов; 95\% ДИ - 95\% доверительный интервал; $\mathrm{P}$ - значимость различий

В таблицах 1 и 2 приведены результаты изучения показателя отношения шансов (ОШ) для каждого параметра, которые показывают во сколько раз шанс иметь изучаемый признак в группе больных ОФ больше, чем в группе МФ КЭ.

Таблийа 2.

Анализ предикторов объективного и неврологического статусов очаговой формы клещевого энцефалита

\begin{tabular}{|c|c|c|c|c|c|}
\hline \multirow{2}{*}{ Предикторы } & \multicolumn{2}{|c|}{$\begin{array}{c}\text { Частота (\%) } \\
\text { в группах больных }\end{array}$} & \multirow{2}{*}{ ОШ (95\% ДИ) } & \multirow{2}{*}{$\begin{array}{c}\chi^{2} \\
\text { или } \\
\text { ТКФ }\end{array}$} & \multirow[b]{2}{*}{$P$} \\
\hline & $\begin{array}{c}\text { ОФ КЭ } \\
n=26\end{array}$ & $\begin{array}{c}\text { МФ КЭ } \\
\mathrm{n}=138\end{array}$ & & & \\
\hline \multicolumn{6}{|l|}{ Объективный статус } \\
\hline СД, > 130 мм. рт. ст. & 40,0 & 7,4 & $8,3(2,1-32,3)$ & 11,4 & $<0,001$ \\
\hline ДД, > 80 мм. рт. ст. & 42,1 & 5,6 & $12,4(2,8-54,2)$ & 14,7 & $<0,001$ \\
\hline Частота пульса, > 80 в мин & 60,0 & 5,6 & $25,5(5,9-110,7)$ & 26,8 & $<0,001$ \\
\hline ЧД, $\geq 20$ в мин & 50,0 & 22,2 & $3,5(1,2-10,4)$ & 5,4 & 0,020 \\
\hline
\end{tabular}


Окончание табл. 2.

\begin{tabular}{|c|c|c|c|c|c|}
\hline Температура тела, $\geq 39,5^{\circ} \mathrm{C}$ & 45,0 & 14,8 & $4,7(1,5-14,9)$ & 7,5 & 0,006 \\
\hline $\begin{array}{l}\text { Продолжительность } \\
\text { лихорадки } \geq 20 \text { дней }\end{array}$ & 56,3 & 24,1 & $4,1(1,3-13,0)$ & 5,9 & 0,014 \\
\hline \multicolumn{6}{|l|}{ Неврологический статус } \\
\hline Нарушение сознания & 83,3 & 13,4 & $32,5(8,6-121,5)$ & 44,2 & $<0,001$ \\
\hline Дезориентация & 50,0 & 5,6 & $17,0(3,9-73,0)$ & 16,9 & $<0,001$ \\
\hline $\begin{array}{l}\text { Нарушение координации } \\
\text { движений }\end{array}$ & 90,0 & 27,8 & $23,4(4,8-113,3)$ & 20,4 & $<0,001$ \\
\hline Нарушение речи & 75,0 & 3,7 & $\begin{array}{c}78,0(13,7- \\
443,3) \\
\end{array}$ & 32,0 & $<0,001$ \\
\hline Нарушение функции ЧН & 50,0 & 5,6 & $17,0(3,9-73,0)$ & 16,9 & $<0,001$ \\
\hline Нистагм & 80,0 & 29,6 & $9,5(2,7-32,9)$ & 15,1 & $<0,001$ \\
\hline $\begin{array}{l}\text { Нарушение произвольных } \\
\text { движений }\end{array}$ & 70,0 & 5,6 & $39,7(8,8-179,0)$ & 30,7 & $<0,001$ \\
\hline $\begin{array}{l}\text { Отрицательные брюшные } \\
\text { рефлексы }\end{array}$ & 60,0 & 3,7 & $39,0(7,3-207,6)$ & 26,6 & $<0,001$ \\
\hline Симптом Ласега & 73,3 & 7,4 & $34,4(7,4-159,1)$ & 26,2 & $<0,001$ \\
\hline Выраженность РЗМ & 81,8 & 46,3 & $5,2(1,0-26,5)$ & 4,6 & 0,032 \\
\hline Симптом Кернига & 75,0 & 26,0 & $8,6(2,6-27,9)$ & 14,8 & $<0,001$ \\
\hline Симптомы Брудзинского & 45,0 & 20,4 & $3,2(1,1-9,6)$ & 4,5 & 0,034 \\
\hline $\begin{array}{l}\text { Продолжительность: } \\
\text { • дезориентации } \geq 3 \text { дней }\end{array}$ & 35,0 & 7,4 & $6,8(1,7-26,5)$ & 8,8 & 0,003 \\
\hline $\begin{array}{l}\text { • нарушения координации } \\
\geq 5 \text { дней }\end{array}$ & 90,0 & 27,8 & $23,4(4,8-113,3)$ & 20,4 & $<0,001$ \\
\hline $\begin{array}{l}\text { • нарушения функции ЧН } \\
\geq 7 \text { дней }\end{array}$ & 85,0 & 40,7 & $8,2(2,2-31,5)$ & 9,8 & 0,001 \\
\hline $\begin{array}{l}\text { • нарушения движений } \\
\geq 4 \text { дней }\end{array}$ & 65,0 & 3,7 & $\begin{array}{l}48,3(8,9- \\
260,4) \\
\end{array}$ & 30,2 & $<0,001$ \\
\hline $\begin{array}{l}\text { - менингеальных симптомов } \\
\geq 10 \text { дней }\end{array}$ & 45,0 & 9,3 & $8,0(2,2-28,7)$ & 12,15 & $<0,001$ \\
\hline
\end{tabular}

Примечание: МФ - менингеальная форма; ОФ - очаговая (менингоэнцефлитическая) форма; ОШ - отношение шансов; 95\%ДИ - 95\% доверительный интервал; $\chi^{2}$ - критерий «хи-квадрат»; Р - значимость различий; ТКФ - точный критерий Фишера; СД - систолическое давление; ДД - диастолическое давление; ЧД - частота дыхания; ПНП - пальце-носовая проба; ЧН - черепные нервы; РЗМ - ригидность затылочных мышц

Установлено, что к числу параметров, имеющих прогностическое значение для развития ОФ КЭ можно отнести: возраст больного старше 41 
года, локализацию присасывания клеща в области головы и шеи, срок поступления больного в стационар после начала заболевания не ранее 14 дня, число сопутствующих заболеваний у пациента 2 и более, а также наличие таких сопутствующих заболеваний как сахарный диабет, гипертоническая болезнь, ишемическая болезнь сердца (ИБС) и ожирение (табл. 1). Установлено, что сахарный диабет регистрировался только у $3,8 \pm 19,1 \%$ больных МФ болезни, у $11,1 \pm 31,4 \%$ больных ОФ без летального исхода и у $83,3 \pm 37,3 \%$ больных, у которых заболевание закончилось летально $(P<0,05)$. Гипертоническая болезнь и ИБС были диагностированы у $5,1 \pm 21,9 \%$ и $3,2 \pm 17,5 \%$ пациентов с МФ соответственно, у $22,2 \pm 41,5 \%$ и $5,6 \pm 22,9 \%$ больных ОФ без летального исхода и у $83,3 \pm 37,3 \%$ умерших больных с ОФ $(P<0,05)$. Кроме того, ожирение 2 степени встречалось у $5,6 \pm 22,9 \%$ выживших больных ОФ и у $50,0 \pm 50,0 \%$ больных ОФ с летальным исходом $(P<0,05)$. Корреляционный анализ с использованием коэффициента взаимной сопряженности (К) позволил выявить статически значимую связь между числом сопутствующих заболеваний у больного и степенью выраженности нарушения сознания: ясное, оглушение, сопор, делирий или кома $(\mathrm{K}=0,64, \mathrm{P}<0,001)$.

Кроме того, установлено, что у больных ОФ статистически значимо чаще, по сравнению с пациентами МФ, была продолжительность таких жалоб как миалгии (более 15 дней), боли в спине (более 19 дней), тошноты и головной боли (свыше 17 дней), чувства онемения конечности и нарушения зрения в виде диплопии или мелькания «мушек» (более 20 дней). Высокую прогностическую ценность как фактор риска ОФ имеют выявление у больного при поступлении в стационар систолического и диастолического давления выше 130 и 80 мм рт. ст. соответственно, частоты пульса выше 80 в мин, частоты дыхательных движений более или равно 20 в мин, а также повышения температуры тела выше или равно $39,5^{\circ} \mathrm{C}$. В неврологическом статусе (табл. 2) в качестве диагностических критериев высокого риска развития ОФ следует обращать особое внимание на появление: дезориентации пациента, любую степень нарушения сознания (от оглушения до комы), нарушение речи (спутанная, нечленораздельная или отсутствует), нарушение координации движений, включающие патологическое изменение походки (пошатывание при ходьбе, ходьба с поддержкой или полная не возможность стоять или ходить), оценку выполнения позы Ромберга и пальце-носовой пробы; нарушение функции III, IV, VI, VII и XII пар черепных нервов; нарушение произвольных движений конечностей (снижение объема выполняемых движений, 
силы мышц, появление гипо- или гипертонуса). Кроме того, у больных ОФ значительно чаще выявлялось отсутствие брюшных рефлексов, положительные симптомы Ласега, Вассермана, Кернига и Брузинского, а также грубая ригидность затылочных мышц. Показано, что пациенты с ОФ заболевания, по сравнению с МФ, статистически значимо чаще имеют продолжительность лихорадки более 20 дней, дезориентации более 3 дней, менингеальных симптомов более 10 дней, нарушение произвольных движений более 4 дней, нарушение координации движений более 5 дней и нарушение функции черепных нервов более 7 дней.

B таблице 3 приведены результаты ROC-анализа и с помощью определения AUC и COV с оценкой чувствительности и специфичности большинства изученных количественных показателей в качестве предикторов ОФ КЭ.

Установлено, что в день поступления больного в стационар «хорошее» качество прогноза высокого риска развития ОФ имели возраст больного более 41 года и систолическое давление выше 130 мм рт. ст.; «среднее» качество продемонстрировали такие предикторы как диастолическое давление более 80 мм рт. ст., частота пульса более 80 в мин, частота дыхательных движений более или равно 20 в мин, а также повышение температуры тела выше или равно $39,5^{\circ} \mathrm{C}$.

Кроме того, при анализе продолжительности отдельных симптомов КЭ «средним» качеством прогностической силы в отношении ОФ обладали сохранение повышенной температуры тела более 20 дней и тошноты более 17 дней; «очень хорошее» качество прогноза ОФ было связано с длительностью нарушения координации движений более 5 дней и патологическим изменением функции черепных нервов более 7 дней, а «отличное» значение как предиктор ОФ имело нарушение произвольных движений более 4 дней. Однако, большинство перечисленных показателей продолжительности того или иного симптома нельзя использовать в качестве ранних предикторов ОФ КЭ.

Поэтому нами предпринята попытка разработать и дать оценку качества прогностической ценности несколько диагностических моделей, которые могли бы быть использованы практическим врачом для раннего прогноза ОФ КЭ.

В таблице 4 приведены результаты логистической регрессионного анализа создания диагностической модели 1. Установлено, что модель 1 имеет «отличное» качество прогноза развития ОФ $(\mathrm{AUC}=0,96$, при стандартной ошибке среднего $(S) \pm 0,02)$. Для каждого показателя в таблице приведены коэффициенты регрессии (B) и указана условная шкала, ко- 
торая позволяет рассчитать сумму баллов для каждого пациента. Установлено, что при сумме баллов 478 и меньше чувствительность составит $85,0 \%$, специфичность - 96,3\%, а отрицательные и положительные прогностические значения $-0,95$ и 0,89 .

Таблица 3.

Чувствительность и специфичность клинических предикторов очаговой формы клещевого энцефалита

\begin{tabular}{|l|c|c|c|}
\hline \multicolumn{1}{|c|}{ Предикторы } & $\begin{array}{c}\text { AUС / Качество } \\
\text { прогноза }\end{array}$ & $\mathrm{COV}$ & $\begin{array}{c}\text { Вероятность ОФ } \\
\text { при значениях } \\
\text { выше СОV, \% }\end{array}$ \\
\hline Возраст, в годах & $0,71 /$ хорошее & 41 & 78,7 \\
\hline СД, мм.рт. ст. & $0,72 /$ хорошее & 130 & 64,0 \\
\hline ДД, мм.рт. ст & $0,66 /$ среднее & 80 & 71,5 \\
\hline Частота пульса, в мин & $0,63 /$ среднее & 80 & 74,1 \\
\hline Частота дыхания, в мин & $0,67 /$ среднее & 20 & 83,2 \\
\hline Температура, ${ }^{\circ} \mathrm{C}$ & $0,62 /$ среднее & 39,5 & 63,3 \\
\hline $\begin{array}{l}\text { Продолжительность } \\
\text { • лихорадки, в днях }\end{array}$ & $0,62 /$ среднее & 20 & 65,7 \\
\hline • тошноты, в днях & $0,62 /$ среднее & 17 & 62,1 \\
\hline $\begin{array}{l}\text { • нарушения координации движе- } \\
\text { ний, в днях }\end{array}$ & $\begin{array}{c}0,88 / \\
\text { очень хорошее }\end{array}$ & 5 & 98,3 \\
\hline • нарушения функции ЧН, в днях & $\begin{array}{c}0,84 / \\
\text { очень хорошее }\end{array}$ & 7 & 97,2 \\
\hline нарушения движений, в днях & $0,90 /$ отличное & 4 & 92,7 \\
\hline
\end{tabular}

Примечание: ROC-анализ (receiver operating characteristic) - приемная характеристика приемника; AUC (area under ROC curve) - площадь под ROC-кривой; COV (cut-off value) - значение оптимального порога отсечения; ОФ - очаговая форма; СД - систолическое давление; ДД - диастолическое давление; ЧН - черепные нервы.

Это означает, что если COV в балльной шкале равен 478, то вероятность развития ОФ составит $85 \%$, а вероятность МФ только $3,7 \%$. В случае получения суммы баллов ниже 405 вероятность развития МФ равна нулю, а ОФ - 55\% (чувствительность - 55,0\%, специфичность - $100 \%$, отрицательные и положительные прогностические значения - 0,86 и 1,0 ). Если COV достигнет 585 баллов и выше, то вероятность МФ составит $40,7 \%$, а вероятность ОФ достигнет 0 (чувствительность равна $100 \%$, специфичность - 59,3\%, а отрицательные и положительные прогностические значения $-1,0$ и 0,47 ). 
Таблииа 4.

Диагностические алгоритмы прогноза очаговой формы КЭ в модели 1

\begin{tabular}{|c|c|c|c|c|c|c|}
\hline Предикторы & Баллы & $\begin{array}{c}\text { В } \\
(95 \% \text { ДИ) }\end{array}$ & $\begin{array}{c}\text { Критерий } \\
\text { Вальда }\end{array}$ & $\begin{array}{c}\text { Log-веро- } \\
\text { ятность }\end{array}$ & $\chi^{2}$ & $P$ \\
\hline Модель 1 & & $1,6(0,5-2,7)$ & 8,5 & $-43,2$ & & 0,004 \\
\hline $\begin{array}{l}\text { Возраст, в годах } \\
<20 \\
20-22 \\
22-27 \\
27-32 \\
32-35 \\
35-41 \\
42-49 \\
49-53 \\
53-69 \\
>69\end{array}$ & $\begin{array}{c}164 \\
151 \\
136 \\
156 \\
164 \\
156 \\
99 \\
133 \\
99 \\
75\end{array}$ & $\begin{array}{c}0,009 \\
(0,001-0,018)\end{array}$ & 5,0 & $-35,6$ & 15,1 & $<0,001$ \\
\hline $\begin{array}{l}\text { День поступле- } \\
\text { ния от начала } \\
\text { болезни } \\
<3 \\
3-4 \\
4-5 \\
5-6 \\
6-7 \\
7-8 \\
8-14 \\
14-15 \\
15-20 \\
>20\end{array}$ & $\begin{array}{c}108 \\
153 \\
193 \\
133 \\
139 \\
133 \\
104 \\
64 \\
138 \\
84\end{array}$ & $\begin{array}{c}0,017 \\
(0,004-0,023)\end{array}$ & 7,5 & $-22,9$ & 10,8 & 0,001 \\
\hline $\begin{array}{l}\text { Пульс, в мин } \\
<64 \\
65-71 \\
72-80 \\
81-92 \\
>92\end{array}$ & $\begin{array}{c}113 \\
130 \\
133 \\
47 \\
26\end{array}$ & $\begin{array}{c}0,014 \\
(0,004-0,024)\end{array}$ & 7,6 & $-28,3$ & 14,6 & $<0,001$ \\
\hline $\begin{array}{l}\text { Дезориентация } \\
\text { - Нет } \\
\text { - Возбужде- } \\
\text { ние } \\
\text { - Делирий }\end{array}$ & $\begin{array}{l}165 \\
102 \\
102\end{array}$ & $1,1(0,15-2,0)$ & 5,2 & $-20,1$ & 5,6 & 0,017 \\
\hline
\end{tabular}

Примечание: В - коэффициент регрессии; 95\%ДИ - 95\% доверительный интервал; $\chi^{2}$ - критерий «хи-квадрат»; $\mathrm{P}$ - значимость различий; СД - систолическое давление 
В таблице 5 приведены результаты логистической регрессии и балльные шкалы для моделей 2 и 3, основанных на результатах изучения неврологического статуса при поступлении больного в стационар.

Таблица 5 . Диагностические алгоритмы прогноза очаговой формы КЭ в моделях 2 и 3

\begin{tabular}{|c|c|c|c|c|c|c|}
\hline Предикторы & Баллы & $\begin{array}{c}\text { В } \\
\text { (95\% ДИ) }\end{array}$ & $\begin{array}{c}\text { Критерий } \\
\text { Вальда }\end{array}$ & $\begin{array}{l}\text { Log-вероят- } \\
\text { ность }\end{array}$ & $\chi^{2}$ & $P$ \\
\hline Модель 2 & & $\begin{array}{c}-8,4 \\
(-9,8--7,1)\end{array}$ & 143,4 & $-43,2$ & & $<0,001$ \\
\hline $\begin{array}{l}\text { Сознание } \\
\text { • Ясное } \\
\text { - Оглушение } \\
\text { - Сопор } \\
\text { - Делирий } \\
\text { - Кома } \\
\end{array}$ & $\begin{array}{c}144 \\
18 \\
18 \\
18 \\
18\end{array}$ & $2,2(0,9-3,5)$ & 11,3 & $-12,9$ & 20,3 & $<0,001$ \\
\hline $\begin{array}{l}\text { Речь } \\
\text { • Норма } \\
\text { • Спутанная } \\
\text { • Отсутствие }\end{array}$ & $\begin{array}{l}124 \\
39 \\
39\end{array}$ & $1,5(0,3-2,7)$ & 5,7 & $-23,1$ & 40,2 & $<0,001$ \\
\hline $\begin{array}{c}\text { Функции ЧН } \\
\text { • Сохранены } \\
\text { • Нарушены }\end{array}$ & $\begin{array}{c}316 \\
-154 \\
\end{array}$ & 8,1 & - & $-12,6$ & 0,6 & \\
\hline Модель 3 & & $\begin{array}{c}-18,9 \\
(-22,0- \\
-15,7)\end{array}$ & 140,9 & $-43,2$ & & $<0,001$ \\
\hline $\begin{array}{l}\text { Сознание } \\
\text { • Ясное } \\
\text { - Оглушение } \\
\text { - Сопор } \\
\text { - Делирий } \\
\text { - Кома } \\
\end{array}$ & $\begin{array}{l}569 \\
517 \\
-596 \\
-566 \\
-566 \\
\end{array}$ & $\begin{array}{c}20,4 \\
(17,2-23,5)\end{array}$ & 160,8 & $-11,9$ & 34,6 & $<0,001$ \\
\hline $\begin{array}{l}\text { Координация } \\
\text { движений } \\
\text { • Норма } \\
\text { • Пошатывание } \\
\text { • Не стоит } \\
\end{array}$ & $\begin{array}{r}532 \\
-27 \\
-562 \\
\end{array}$ & 19,1 & 0 & $-9,0$ & 5,9 & 0,015 \\
\hline $\begin{array}{l}\text { Брюшные реф- } \\
\text { лексы } \\
\text { • Есть } \\
\text { • Не выявля- } \\
\text { ются } \\
\end{array}$ & $\begin{array}{l}-3 \\
-35 \\
\end{array}$ & 0,6 & 0,6 & $-29,3$ & 27,8 & $<0,001$ \\
\hline
\end{tabular}


Обе модели имеют «отличное» качество прогноза развития ОФ (AUC $=0,94$ для модели 2 и 0,98 для модели 3 , при стандартной ошибке среднего $(S) \pm 0,02)$. Показано, что при сумме баллов 373 в модели 2 и -67 в модели 3 для прогноза ОФ чувствительность составит $85,0 \%$, а специфичность $98,1 \%$ (вероятность ОФ составит $85 \%$, а вероятность МФ только 1,85\%). В случае получения суммы баллов -67 для модели 2 и -1123 для модели 3 вероятность развития МФ равна нулю, а ОФ - 50\% (чувствительность $50,0 \%$, специфичность - 100\%). Если COV достигнет 584 баллов для модели 2 и 750 баллов и выше для модели 3, то вероятность МФ составит $100 \%$, а вероятность ОФ снизится до нуля.

Проведенное исследование с помощью сложных инструментов статистического анализа позволило выделить наиболее прогностически значимые для ранней диагностики ОФ параметры объективного и неврологического статусов, на которые лечащему врачу следует обращать особое внимание при поступлении больного в стационар. К ним можно отнести: возраст больного, частоту пульса, показатели систолического давления, нарушение речи и сознания, координации движений, функции черепных нервов и исчезновение брюшных рефлексов. Кроме того, по нашему мнению, к числу дополнительных факторов существенно повышающих риск летального исхода при ОФ КЭ можно отнести наличие у больного сахарного диабета, гипертонической болезни, ишемической болезни сердца и ожирения.

В настоящее время рядом авторов также были проанализированы предикторы тяжелых форм КЭ [2, 4, 9-17]. Однако, в отличие от данной работы большинство авторов при выборе прогностических критериев ОФ КЭ ограничивались стандартными методами статистического анализа ( $t$-критерий Стьюдента и критерий значимости гипотезы) и не прибегали к методам логистической регрессии, ROC-анализа или к построению шкал балльной клинической оценки.

Среди данных эпидемиологического анамнеза и клинического обследования, имеющих прогностическое значение для высокого риска ОФ, некоторые исследователи приводили данные об отсутствии факта присасывания клеща или множественных укусов переносчика, возраст пациентов 45-60 лет и старше, появление на первой неделе болезни психопатологических симптомов, судорог, тахипноэ, нарушения координации движений [4, 9-12]. Другие авторы, напротив, отмечали, что у больных КЭ 15-35 лет доля очаговых форм значительно выше, чем у пациентов старше 59 лет [13]. Кроме того, некоторые авторы указывали в качестве 
предикторов ОФ нарастание или сохранение фебрильной температуры, наличие и выраженность ригидности затылочных мышц и симптома Кернига в течение первых трех дней болезни $[2,14,15]$. В ряде работ было установлено, что для ОФ был характерен длительный лихорадочный период, головная боль, миалгии, тошнота и рвота [13]. Некоторые авторы приводили данные о роли сопутствующей патологии как факторов риска ОФ, перечисляя главным образом, частые ОРВИ и ангины в анамнезе, наличие исходной патологии нервной системы, соматическую патологию дегенеративного характера, хронический алкоголизм, без использования адекватной оценки вклада каждого из этих заболеваний в тяжесть и исход течения КЭ $[2,13,15]$. В публикации исследователей из Словении приведена разработанная ими шкала балльной клинической оценки тяжести течения КЭ (легкая, средней степени тяжести и тяжелая), включавшая продолжительность головной боли, лихорадки, тошноты, менингеальных симптомов, тремор, наличие парезов конечностей, когнитивных расстройств и нарушения сознания $[16,17]$. Однако эта модель, в отличие от разработанных нами алгоритмов, мало пригодна для ранней диагностики ОФ КЭ. Кроме того, известно, что клиническая картина КЭ весьма вариабельна, что, прежде всего, может зависеть от генотипов вирусов, циркулирующих в том или ином географическом регионе, и многих других факторов [18-20]. Поэтому создание математических моделей на основе анализа данных, полученных из максимально возможного количества историй болезни в различных регионах в будущем, возможно, позволит создать универсальную модель ранней диагностики ОФ.

\section{Заключение}

Таким образом, результаты настоящего исследования показали возможность улучшения диагностики, раннего прогнозирования развития и дифференцировки ОФ от МФ КЭ благодаря использованию разработанных моделей и диагностических алгоритмов. Практическое применение этих моделей поможет врачу в определении тактики ведения пациентов при поступлении в стационар.

Информация о конфликте интересов. Авторы декларируют отсутствие явных и потенциальных конфликтов интересов, связанных с публикацией настоящей статьи.

Информация о спонсорстве. Исследование выполнено при финансовой поддержке гранта РФФИ (№ 16-40-700149). 


\section{Список литературы}

1. Эпидемиологическая ситуация по клещевому энцефалиту в Томской области (2007-2009 гг.) / Удинцева И.Н., Полторацкая Т.Н., Шихин А.В., Попонина А.М., Жукова Н.Г., Лукашова Л.В., Малышева Л.А. // Вестник УГМА. 2010. № 21. C. 208-209. URL: https://elibrary.ru/item.asp?id=25490019

2. Клинико-лабораторные аспекты ранней диагностики менингеальной и менингоэнцефалитической форм клещевого энцефалита / Толоконская Н.П., Спиридонова Э.А., Казакова Ю.В., Проворова В.В., Бурмистрова Т.Г. // Бюллетень Сибирской медицины. 2008. Приложение 1. С. 12-19.

3. Sensitivity and specificity of a novel classifier for the early diagnosis of dengue / Tuan N.M., Nhan H.T., Chau N.V., Hung N.T., Tuan H.M., Tram T.V., Ha Nle D., Loi P., Quang H.K., Kien D.T., Hubbard S., Chau T.N., Wills B., Wolbers M., Simmons C.P. // PLoS Negl Trop Dis. 2015. vol. 9(4). e0003638. doi: 10.1371/journal.pntd.0003638.

4. Клинико-эпидемиологические особенности очаговых форм клещевого энцефалита / Любезнова О.Н., Бондаренко А.Л., Контякова Е.Л., Тихомолова Е.Г., Попонин Н.М. // Медицинский альманах. 2015. № 5 (40). С. 156-158. URL: https://elibrary.ru/item.asp?id=25076421

5. Боровиков В.П. Популярное введение в современный анализ данных в системе STATISTICA. Учебное пособие для вузов. М.: Горячая линия - Телеком, 2013. $288 \mathrm{c}$.

6. Statistical methods in biology: design and analysis of experiments and regression / Welham S.J., Gezan S.A., Clark S.J., Mead A. NY: CRC Press Taylor \& Francis Group, 2015. 563 p.

7. Siddiqi N. Credit risk scorecards: developing and implementing intelligent credit scoring. NJ: John Wiley \& Sons, 2006. 254 p. doi: 10.1002/9781119201731

8. Fawcett T. An introduction to ROC analysis // Pattern Recognition Letters. 2006. vol. 27 (8), pp. 861-874. doi.org/10.1016/j.patrec.2005.10.010

9. Клиническая характеристика клещевого энцефалита в Кировской области / Бондаренко А.Л., Контякова Е.Л., Тихомолова Е.Г., Зыкова И.В., Коржова И.В., Аббасова С.В., Кропанев А.В. // Инфекционные болезни. 2010. T.8. №1. C. 83-87. URL: https://elibrary.ru/item.asp?id=15228904

10. Волкова Л.И., Ковтун О.П. Возрастные аспекты эпидемиологии и клиники клещевого энцефалита // Журнал неврологии и психиатрии им. С.С. Корсакова. 2008. T. 108. № 10. C. 61-65. URL: https://elibrary.ru/item.asp?id=11633451

11. Любезнова О.Н., Бондаренко А.Л. Клинико-эпидемиологические аспекты клещевого энцефалита в эндемичном регионе Европейской части России // Журнал инфектологии. 2016. Т. 8. № 2. С. 32-39. URL: https://elibrary.ru/ item. asp?id $=26415837$ 
12. Мельникова О.В., Андаев Е.И. Связь манифестных случаев клещевого вирусного энцефалита с некоторыми демографическими, социальными и экологическими факторами // Эпидемиология и вакцинопрофилактика. 2014. T. 77. № 4. C. 37-45. URL: https://elibrary.ru/item.asp?id=21836911

13. Значение клинических признаков и их сочетания в ранней диагностике клинической формы клещевого энцефалита / Проворова В.В., Толоконская Н.П., Спиридонова Э.А., Казакова Ю.В. // Бюллетень Сибирской медицины. 2008. Приложение 1. С. 7-11.

14. Конькова-Рейдман А.Б., Злобин В.И. Клинико-эпидемиологическая характеристика клещевого энцефалита на Южном Урале // Сибирский медицинский журнал (Иркутск). 2011. T. 103. № 4. C. 92-95. URL: https://elibrary.ru/ item.asp?id=16969250

15. Толоконская Н.П., Казакова Ю.В., Проворова В.В. Значение исходного статуса пациентов в течении клещевого энцефалита и его прогнозе // Инфекционные болезни. 2007. Т. 5. № 2. С. 42-47. URL: https://elibrary.ru/item. asp?id $=9588713$

16. Quantitative evaluation of the severity of acute illness in adult patients with tick-borne encephalitis / Bogovic P., Logar M., Avsic-Zupanc T., Strle F., LotricFurlan S. // Biomed Res Int. 2014. vol. 2014. 841027. doi: 10.1155/2014/841027

17. Tick-borne encephalitis in Slovenia from 2000 to 2004: comparison of the course in adult and elderly patients / Logar M., Bogovic P., Cerar D., AvsicZupanc T., Strle F. // Wiener KlinischeWochenschrift. 2006. vol. 118, no. 2122, pp. 702-707. doi: 10.1007/s00508-006-0699-6

18. Молекулярная эпидемиология вируса клещевого энцефалита: географическая вариабельность, определяемая методом молекулярной гибридизации / Демина Т.А., Джиоев Ю.П., Верхозина М.М., Козлова И.В., Ткачев С.Е., Дорощенко Е.К., Лисак О.В., Злобин В.И. // Эпидемиология и вакцинопрофилактика. 2009. Т. 46. № 3. С. 27-39. URL: https://elibrary.ru/item.asp?id=12774761

19. Морозова О.В., Бахвалова В.Н. Природные циклы и клещевой энцефалит // В мире научных открытий. 2010. № 2-1. С. 31-37. https://elibrary.ru/item. asp?id $=13295368$

20. Tick-borne encephalitis virus - a review of an emerging zoonosis / Mansfield K. L., Johnson N., Phipps L. P., Stephenson J. R., Fooks A. R., Solomon T. // Journal of General Virology. 2009. vol. 90. Pt. 8. pp. 1781-1794. doi: 10.1099/ vir.0.011437-0

\section{References}

1. Udinceva I.N., Poltorackaja T.N., Shihin A.V., Poponina A.M., Zhukova N.G., Lukashova L.V., Malysheva L.A. Jepidemiologicheskaja situacija po klesh- 
hevomu jencefalitu v Tomskoj oblasti (2007-2009 gg.) [The epidemiological situation of tick-borne encephalitis in the Tomsk region (2007-2009)]. Vestnik Ural'skoj gosudarstvennoj medicinskoj akademii [Bulletin of the Ural State Medical Academy], 2010, no. 21, pp. 208-209.

2. Tolokonskaja N.P., Spiridonova Je.A., Kazakova Ju.V., Provorova V.V., Burmistrova T.G. Kliniko-laboratornye aspekty rannej diagnostiki meningeal'noj i meningojencefaliticheskoj form kleshhevogo jencefalita [Clinical and laboratory aspects of early diagnosis of meningeal and meningoencephalitic forms of tickborne encephalitis]. Bjulleten' Sibirskoj mediciny [Bulletin of Siberian Medicine], 2008, Suppl. 1, pp. 12-19.

3. Tuan N.M., Nhan H.T., Chau N.V., Hung N.T., Tuan H.M., Tram T.V., Ha Nle D., Loi P., Quang H.K., Kien D.T., Hubbard S., Chau T.N., Wills B., Wolbers M., Simmons C.P. Sensitivity and specificity of a novel classifier for the early diagnosis of dengue. PLoS Negl Trop Dis., 2015, vol. 9(4), e0003638. doi: 10.1371/ journal.pntd.0003638.

4. Ljubeznova O.N., Bondarenko A.L., Kontjakova E.L., Tihomolova E.G., Poponina N.M. Kliniko-jepidemiologicheskie osobennosti ochagovyh form kleshhevogo jencefalita [Clinical and epidemiological peculiarities of foci forms of tick-borne encephalitis]. Medicinskij al'manah [Medical Almanac], 2015, no. 5 (40), pp. 156-158.

5. Borovikov V. P. Populjarnoe vvedenie v sovremennyj analiz dannyh $v$ sisteme STATISTICA [A popular introduction to modern data analysis in the STATISTICA system]. Moscow: Gorjachaja linija-Telekom, 2013. 288 p.

6. Welham S.J., Gezan S.A., Clark S.J., Mead A. Statistical methods in biology: design and analysis of experiments and regression. NY: CRC Press Taylor \& Francis Group, 2015. 563 p.

7. Siddiqi N. Credit risk scorecards: developing and implementing intelligent credit scoring. NJ: John Wiley \& Sons, 2006. 254 p. doi: 10.1002/9781119201731

8. Fawcett T. An introduction to ROC analysis. Pattern Recognition Letters, 2006, vol. 27 (8), pp. 861-874. doi.org/10.1016/j.patrec.2005.10.010

9. Bondarenko A.L., Kontjakova E.L., Tihomolova E.G., Zykova I.V., Korzhova I.V., Abbasova S.V., Kropanev A.V. Klinicheskaja harakteristika kleshhevogo jencefalita $v$ Kirovskoj oblasti [Clinical characteristic of tick-borne encephalitis in the Kirov region]. Infekcionnye bolezni [Infectious Diseases], 2010, vol.8, no. 1. pp. 83-87.

10. Volkova L.I., Kovtun O.P. Vozrastnye aspekty jepidemiologii i kliniki kleshhevogo jencefalita [Age aspects of epidemiology and clinical presentations of tick-borne encephalitis] Zhurnal nevrologii i psihiatrii im. S.S. Korsakova [Journal of Neurology and Psychiatry behalf SS. Korsakov], 2008, vol. 108, no. 10, pp. 61-65. 
11. Ljubeznova O.N., Bondarenko A.L. Kliniko-jepidemiologicheskie aspekty kleshhevogo jencefalita $\mathrm{v}$ jendemichnom regione Evropejskoj chasti Rossii [The clinical and epideiological features of tick-borne encephalitis at the endemical region of Russia's European part]. Zhurnal infektologii [Journal of Infectology]. 2016. vol. 8, no. 2, pp. 32-39.

12. Mel'nikova O.V., Andaev E.I. Svjaz' manifestnyh sluchaev kleshhevogo virusnogo jencefalita s nekotorymi demograficheskimi, social'nymi i jekologicheskimi faktorami [The manifest tick-borne encephalitis cases and their relationship with some demographic, social and ecological factors]. Jepidemiologija $i$ vakcinoprofilaktika [Epidemiology and vaccine prevention], 2014, vol. 77, no. 4, pp. 37-45.

13. Provorova V.V., Tolokonskaja N.P., Spiridonova Je.A., Kazakova Ju.V. Znachenie klinicheskih priznakov $\mathrm{i}$ ih sochetanija $\mathrm{v}$ rannej diagnostike klinicheskoj formy kleshhevogo jencefalita [The significance of clinical signs and their combination in the early diagnosis of the clinical form of tick-borne encephalitis]. Bjulleten 'Sibirskoj mediciny [Bulletin of Siberian Medicine], 2008, Suppl. 1, pp. 7-11.

14. Kon'kova-Rejdman A.B., Zlobin V.I. Kliniko-jepidemiologicheskaja harakteristika kleshhevogo jencefalita na Juzhnom Urale [Clinical and epidemiologic al characteristics of tick-borne encephalitis in the Southern Urals]. Sibirskij medicinskij zhurnal (Irkutsk) [Siberian Medical Journal (Irkutsk)], 2011, vol. 103, vol. 4, pp. 92-95.

15. Tolokonskaja N.P., Kazakova Ju.V., Provorova V.V. Znachenie ishodnogo statusa pacientov $\mathrm{v}$ techenii kleshhevogo jencefalita i ego prognoze [The role of the initial status of patients in course and prognosis of tick-borne encephalitis]. Infekcionnye bolezni [Infectious Diseases], 2007, vol. 5, no. 2, pp. 42-47.

16. Bogovic P., Logar M., Avsic-Zupanc T., Strle F., Lotric-Furlan S. Quantitative evaluation of the severity of acute illness in adult patients with tick-borne encephalitis. Biomed Res Int., 2014, vol. 2014, 841027. doi: 10.1155/2014/841027

17. Logar M., Bogovic P., Cerar D., Avsic-Zupanc T., Strle F. Tick-borne encephalitis in Slovenia from 2000 to 2004: comparison of the course in adult and elderly patients. Wiener KlinischeWochenschrift, 2006, vol. 118, no. 21-22, pp. 702-707. doi: 10.1007/s00508-006-0699-6

18. Demina T.A., Dzhioev Ju.P., Verhozina M.M., Kozlova I.V., Tkachev S.E., Doroshhenko E.K., Lisak O.V., Zlobin V.I. Molekuljarnaja jepidemiologija virusa kleshhevogo jencefalita: geograficheskaja variabel'nost', opredeljaemaja metodom molekuljarnoj gibridizacii [Molecular epidemiology of tick-borne encephalitis virus: geographic variability determined through the method of molecular hybridization]. Jepidemiologija i vakcinoprofilaktika [Epidemiology and vaccine prevention], 2009, vol. 46, no. 3, pp. 27-39. 
19. Morozova O.V., Bahvalova V.N. Prirodnye cikly i kleshhevoj jencefalit [Natural cycles and tick-borne encephalitis]. Vmire nauchnyh otkrytij [In the world of scientific discoveries], 2010, no. 2-1, pp. 31-37.

20. Mansfield K.L., Johnson N., Phipps L.P., Stephenson J.R., Fooks A.R., Solomon T. Tick-borne encephalitis virus - a review of an emerging zoonosis. Journal of General Virology, 2009, vol. 90, Pt. 8, pp. 1781-1794. doi: 10.1099/vir.0.011437-0

\section{ДАННЫЕ ОБ АВТОРАХ}

Ильинских Екатерина Николаевна, д.м.н., доцент, профессор кафедры инфекционных болезней и эпидемиологии Федеральное государственное бюджетное образовательное учреждение выстего образования «Сибирский государственный медииинский университет»

Московский тракт, 2, г. Томск, 634050, Российская Федерация infconf2009@mail.ru

Ильинских Николай Николаевич, д.б.н., профессор, профессор кафедры биологии и генетики Федеральное государственное бюджетное образовательное учреждение высшего образования «Сибирский государственный медицинский университет»

Московский тракт, 2, г. Томск, 634050, Российская Федерация nauka-tomsk@yandex.ru

Замятина Евгения Владимировна, ассистент кафедры инфекционных болезней и эпидемиологии

Федеральное государственное бюджетное образовательное учреждение выстего образования «Сибирский государственный медицинский университет»

Московский тракт, 2, г. Томск, 634050, Российская Федерация e_zamyt@mail.ru

\section{DATA ABOUT THE AUTHORS}

Ilyinskikh Ekaterina Nikolaevna, Dr. of Med. Sc., A.P., Professor of the Department of Infectious Diseases and Epidemiology Siberian State Medical University 2, Moskovskiy trakt, Tomsk, 634050, Russian Federation infconf2009@mail.ru 
SPIN-code: $5245-5958$

ORCID: 0000-0001-7646-6905

ResearcherID: P-1653-2016

Scopus Author ID: 6602611268

Ilyinskikh Nicolai Nikolayevich, Dr. Biol. Sc., Prof., Professor of the Department of Biology and Genetics

Siberian State Medical University

2, Moskovskiy trakt, Tomsk, 634050, Russian Federation

nauka-tomsk@yandex.ru

SPIN-code: 1204-3138

ORCID: 0000-0003-1014-1096

ResearcherID: A-5512-2016

Scopus Author ID: 6603805491

Zamyatina Evgeniya Vladimirovna, Assistant Professor of the Department of Infectious Diseases and Epidemiology

Siberian State Medical University

2, Moskovskiy trakt, Tomsk, 634050, Russian Federation

e_zamyt@mail.ru

SPIN-code: 3594-0609

ORCID: 0000-0001-7579-8975

ResearcherID: S-3641-2016 